\title{
Distal Migration of a Self-Expandable Metal Oesophageal Stent, Presenting As Constipation
}

Self-expanding metal stents form an important part of the palliative management of malignant dysphagia of the oesophagus [1]. Different stent types can be associated with varying complications; metal stents are particularly linked with tumour ingrowth and distal migration [2]. We report a case of distal stent migration leading to complications elsewhere in the gastrointestinal tract, and the problems encountered in dealing with it.

A 62-year-old woman with known diverticular disease presented to the emergency unit with a 6-day history of constipation and left-sided abdominal discomfort. At 2 months prior to this she had undergone endoscopic insertion of a 9-cm covered expandable metallic stent (Ultraflex, Boston Scientific, Galway, Ireland) for an inoperable stage III tumour of the lower oesophagus. The stent did not encroach into the gastro-oesophageal junction.

On emergency admission, an abdominal radiograph showed the presence of the oesophageal stent in the proximal sigmoid colon, with no signs of intestinal obstruction (Figure 1). The patient opened her bowels spontaneously and her pain subsided. She was well enough to be discharged home 2 days later, with laxatives. At 2 weeks following discharge, a flexible sigmoidoscopy confirmed the presence of the metallic stent embedded in the proximal sigmoid colon amongst several large diverticulae (Figure 2 ). It was not possible to safely remove the stent endoscopically because of difficulty in manoeuvring it free from the bowel wall and the surrounding diverticulae. It was decided that the stent should be left where it was, since the patient was no longer experiencing the symptoms of constipation.

This case shows that a self-expandable metallic stent can pass painlessly along the gastrointestinal tract until it becomes lodged in a sigmoid colon containing numerous large diverticulae. If a metal stent is found to have migrated distally, a dilemma arises about whether to leave the

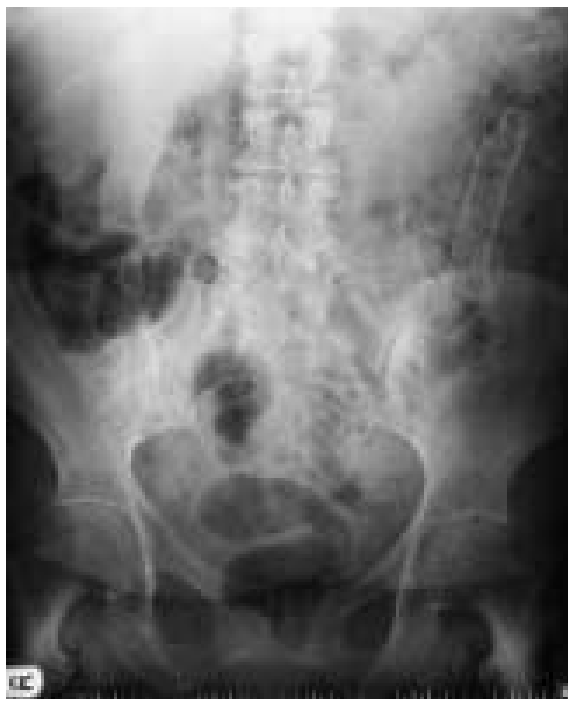

Figure 1 Supine abdominal radiograph showing metal oesophageal stent in left colon.

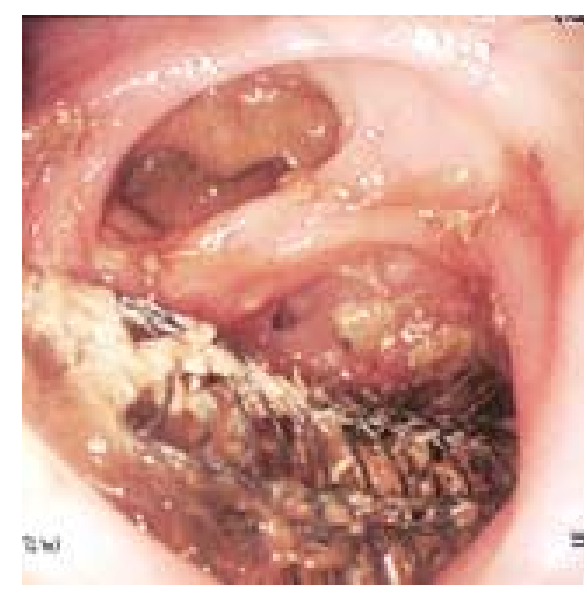

Figure 2 Proximal sigmoid colon at endoscopy, displaying metal oesophageal stent and large diverticulae.

stent in situ in the stomach or to remove it. In a recent study of distally migrated stents [3], it was elected to leave 13 metal stents in the stomach; stent removal was required in only one patient, whilst no severe complications occurred in the others. No data are available on the management of stents that have migrated beyond the ileocaecal valve.
The presence of multiple large sigmoid diverticulae certainly made retrieval of the stent hazardous in this patient. Re-stenting has not been carried out because of recent tumour extension into the stomach and she has undergone successful palliation with argon beam therapy. She continues to take stool-softening laxatives, and to date still has no symptoms arising from the oesophageal stent embedded in her lower gastrointestinal tract.

\section{G. L. Williams ${ }^{1}$, K. Ragunath ${ }^{2}$,} M. Davies ${ }^{1}$, J. S. Harvey ${ }^{1}$, G. A. O. Thomas ${ }^{2}$ ${ }^{1}$ Department of Surgery, University

Hospital of Wales, Cardiff, UK

2 Department of Gastroenterology, University Hospital of Wales, Cardiff, UK.

\section{References}

${ }^{1}$ Cowling MG, Hale H, Grundy A. The use of self expanding metal stents in the management of oesophageal strictures. Br J Surg 1998; 85: $264-246$

${ }^{2}$ Leiper K, Morris A. Treatment of oesophago-gastric tumours. Endoscopy 2002; 34: 139-145

${ }^{3}$ De Palma GD, Iovino P, Catanzano C. Distally migrated esophageal self-expanding metal stents: wait and see or remove? Gastrointest Endosc 2001; 53: $96-98$

\section{Corresponding Author}

\section{G. L. Williams, MB BCh}

Department of General Surgery,

University Hospital of Wales

Heath Park

Cardiff

UK

Fax: $\quad$ +44-29-20742954

E-mail: geth_williams@yahoo.co.uk 